\title{
Making twist-free surfaces by Magnetic Assisted Ball Burnishing
}

\author{
Zsolt Ferenc Kovács ${ }^{1, a}{ }^{*}$, Zsolt János Viharos ${ }^{2, b}$ and János Kodácsy',c \\ ${ }^{1}$ Department of Manufacturing Science and Technology, Budapest University of Technology and \\ Economics, Budapest, $\mathrm{H}-1111$ Hungary \\ ${ }^{2}$ Institute for Computer Science and Control of the Hungarian Academy of Sciences, Budapest H- \\ 1111 Hungary \\ 1, 3 Pallas Athene University, GAMF Faculty, Dep. of Vehicle Technology, Kecskemét H-6000 \\ Hungary \\ a kovacs.zsolt@gamf.kefo.hu, b viharos.zsolt@sztaki.mta.hu, ${ }^{c}$ kodacsy.janos@gamf.kefo.hu
}

Keywords: Magnetism, finishing, polishing, ball burnishing, twist-free.

\begin{abstract}
As a well-known conventional finishing process, the grinding is commonly used to manufacture seal mating surfaces and bearing surfaces. It would lead to generate another finishing machining, which more cost- and energy-efficient, so the grinding process could be replaced by machining with ball burnishing or special type of polishing. The machined surfaces by turning or grinding usually have twist structure on the surfaces, which can convey lubricants such as conveyor screw. To avoid this phenomenon have to use special kind of techniques or machine, for example, rotation turning, tangential turning, ultrasonic protection or special toll geometries. All of these solutions have a high cost and difficult usability. In this paper, the authors describe a system and summarize the results of the experimental research carried out mainly in the field of Magnetic Abrasive Polishing (MAP) and Magnetic Assisted Ball Burnishing (MABB). These technologies are simple and also cheap while result the twist-free surfaces. During the tests, C45 normalized steel was used as workpiece material which was machined by simple and Wiper geometrical turning inserts in a CNC turning lathe. After the turning was used the MAP and MABB technologies to reduce the twist of surfaces. The evaluation was completed by advanced measuring and IT equipment.
\end{abstract}

\section{Introduction}

The conventional process chain for the production of rotationally symmetric components with a high level of hardness, such as crankshafts and camshafts, is characterized by several manufacturing processes, such as turning and grinding. Problem with these conventional process are to creates twisted structure on the surfaces. The reason for this phenomenon is that the feed motion of the tool will cause twist structures, which will then lead to the conveying effect of lubricant between contact surfaces and sealing or plain bearing.

Several studies have investigated the twist-free surfaces and the prevention of twist surface, for prevention was use tangential turning, vibration-processing methods or start-stop turning [1, 2, 3, 4, $5,6]$. These machining processes are productive, but it have also negative side because all of it is requiring special machine or machining strategy. The problem with this that it can be used for only one processing (making a twist-free surface) which in some case not economical.

In this study the authors to create a twist-free surfaces analyses the possibility of Magnetic Abrasive Polishing (MAP) and Magnetic Assisted Ball Burnishing (MABB). Denomination Magnetism Aided Machining (MAM) comprises a number of relatively new industrial machining processes (mainly finishing and surface improving) developed presently, too. MAM is effective among others - for polishing, deburring and burnishing of cylindrical and flat (in some cases even 3D surfaces) metal parts. The magnetic force makes these processes simpler and more productive 
because the machining force is generated by an adjustable electromagnetic field between two magnetic poles within the working area ensuring the necessary pressure and speed difference between the tools (abrasive grains, pellets or rolls) and the workpiece.

\section{Structure of twist surface}

Twist structures are characterized by microscopic structures which are comparable with a thread structure on a shaft surface. Figure 1 shows the surface of a turned shaft schematically. The parameters are described in the Mercedes-Benz standard MBN 31007-7 in 2009. [7, 8, 9]
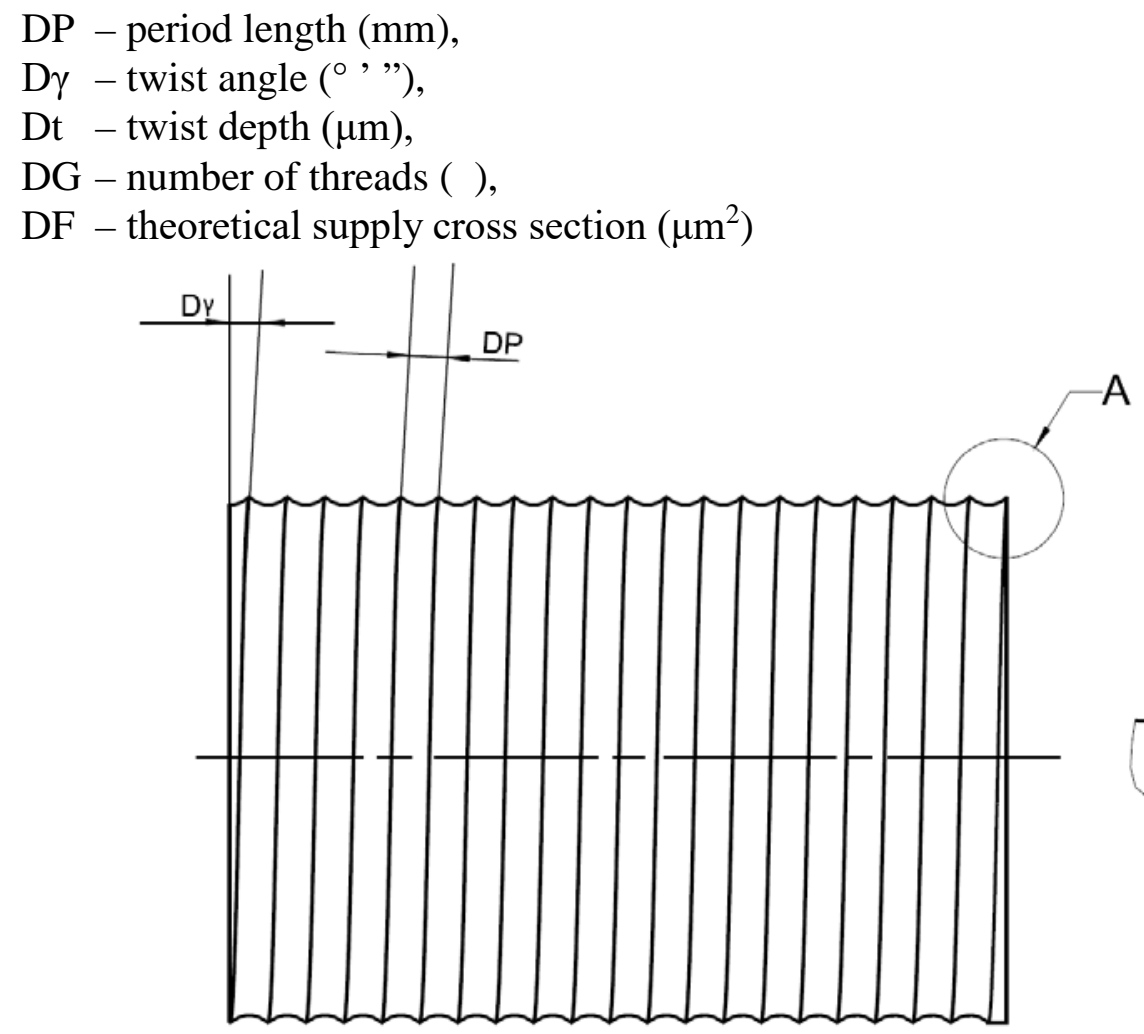

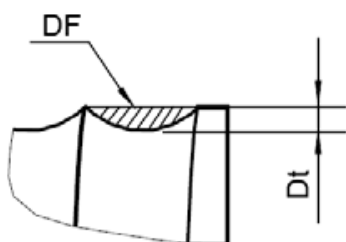

A

Fig. 1. Twisted surface after turning [4]

These parameters are mostly depends on the process and tool parameters (like feed or nose radius etc.). During the rotation of a turned shaft, the liquid entrains in the circumferential direction and is deflected axially because of the twist structures. [8]

The industry is currently looking for alternative manufacturing processes, for example hard turning, milling, burnishing or laser polishing. Besides these processes there are two similar technologies, the MAP and the MABB which are also able to produce twist-free surface.

\section{Magnetic Abrasive Polishing (MAP)}

The polishing as finishing operations is one of the most important final machining process. It is suitable to decreases of surface roughness and increases of resistance against wear, corrosion and mechanical loadings.

Magnetic abrasives are emerging as important finishing methods for metals. MAP is one such unconventional finishing process which is recently developed to produce efficiently and economically good quality finish on internal and external surfaces of tubes as well as flat surfaces made of magnetic or non-magnetic materials. In this process, usually use ferromagnetic particles are sintered with fine abrasive particles (Al2O3, SiC, CBN or diamond), furthermore homogeneously mixed loose ferromagnetic and abrasive particles are also used in certain applications. [10]

Since the magnitude of machining force caused by the magnetic field is low but controllable, a mirror like surface finish (Ra value in the range of nano-meter) is obtained. In MAP, mirror 
finishing is realized and burrs are removed without lowering the accuracy of the shape. This fine finishing technology using magnetic abrasives have a wide range of applications. The surface finishing, deburring and precision rounding of the workpiece can be done simultaneously. The MAP equipment for cylindrical surfaces was adapted to an universal engine lathe (Fig. 2.). [11]
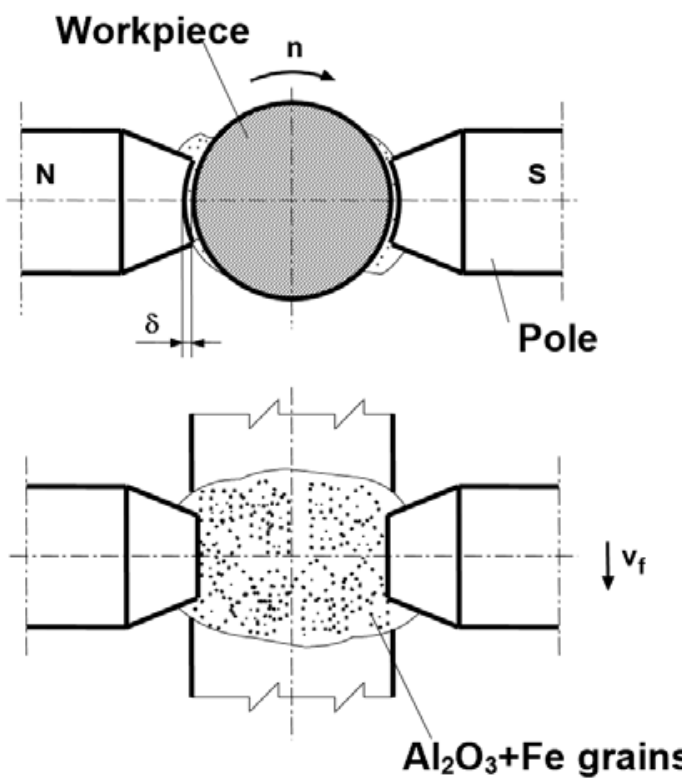

a)

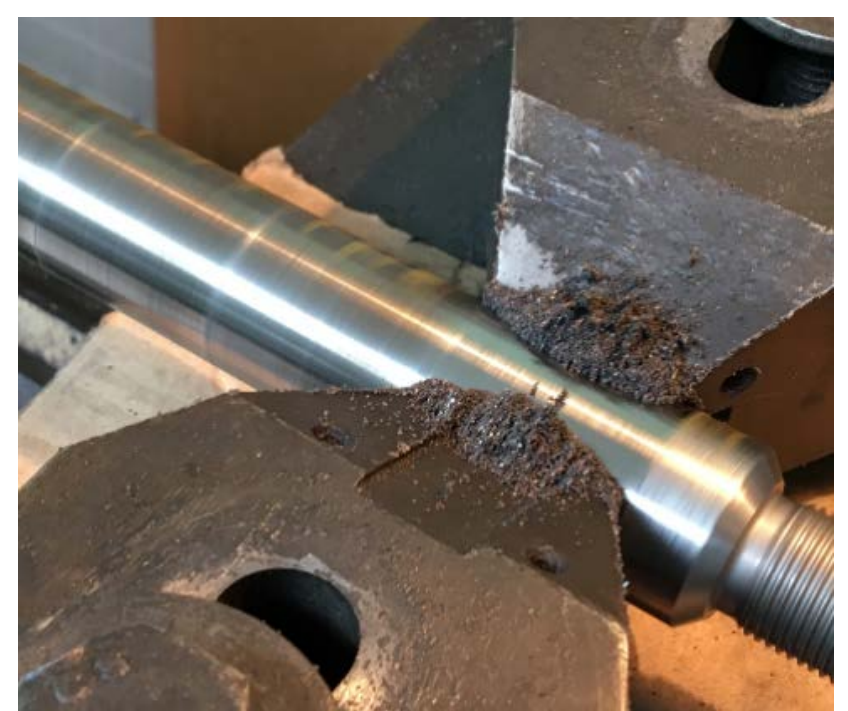

b)

Fig. 2. Process of MAP [7]

In MAP operation, workpiece is kept between two magnets pole. The air gap $(\delta)$ between the workpiece and the magnet, is filled with magnetic abrasive particles is usually made up of ferromagnetic particles are sintered with fine abrasive particles $\left(\mathrm{Al}_{2} \mathrm{O}_{3}, \mathrm{SiC}, \mathrm{CBN}\right.$ or diamond), furthermore homogeneously mixed loose ferromagnetic and abrasive particles are also used in certain applications. [12]

Jain et al [13] have studied the relationship between the working gap and material removal. About their result the material removal versus working gap relationship shows a maximum at a working gap of about $0.5 \mathrm{~mm}$. (Fig. 3.)

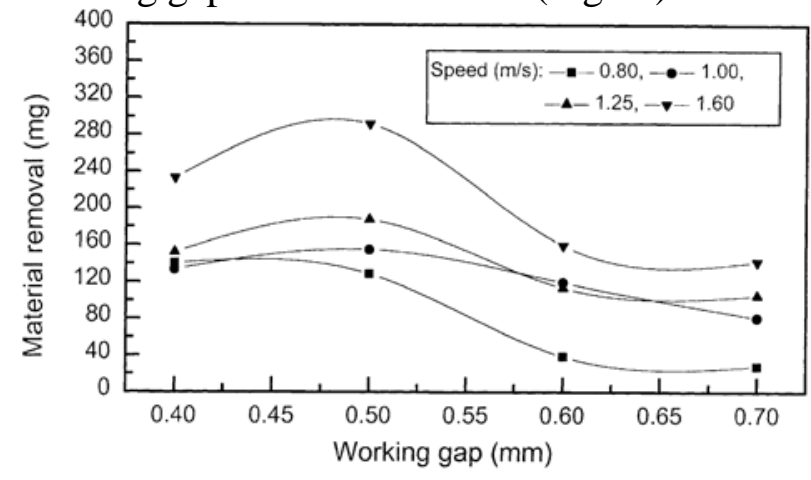

a)

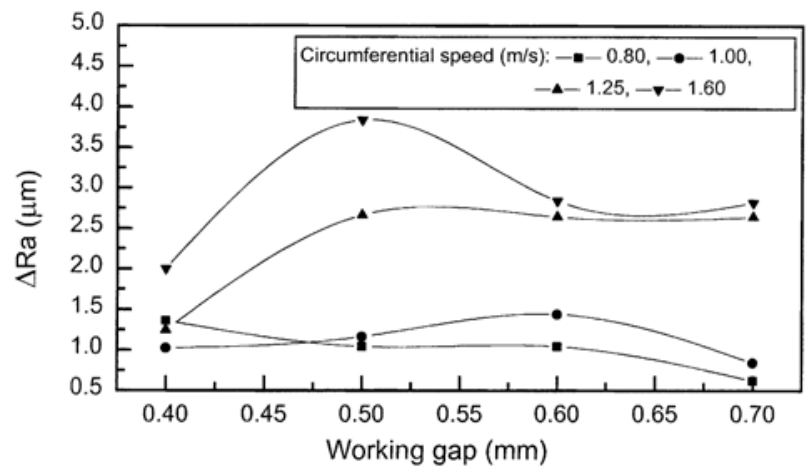

b)

Fig. 3. Effect of working gap on a) material removal and b) surface roughness at different circumferential speeds of the workpiece [13]

\section{Magnetic Assisted Ball Burnishing (MABB)}

The main goal of Ball burnishing is to achieve high-quality smooth surfaces or surfaces with predefined surface finish. One or more balls plastify and deform the workpiece's surface layer. This process is used when the goal is to either achieve a high-quality surface finish or when a pre-defined surface finish cannot be achieved by machining. [11] 
Almost all processes for the manufacturing of high-quality surfaces can be replaced by ball burnishing (e.g. fine turning, grinding, superfinishing, lapgrinding). This proven process entails considerable technological and economic advantages for surfaces in the roughness area $\mathrm{Rz}<10 \mu \mathrm{m}$.

For ball burnishing was applying mechanical force to press the burnishing ball onto the surfaces. To avoid the harmful deformation by mechanic pressing the necessary pressure and relative speed between the tools and the workpiece are ensured by the magnetic force. This is the Magnetic Assisted Ball Burnishing (MABB) process. [11]

The magnetic ball burnishing equipment for cylindrical surfaces was adapted to an universal engine lathe (Fig. 4.)

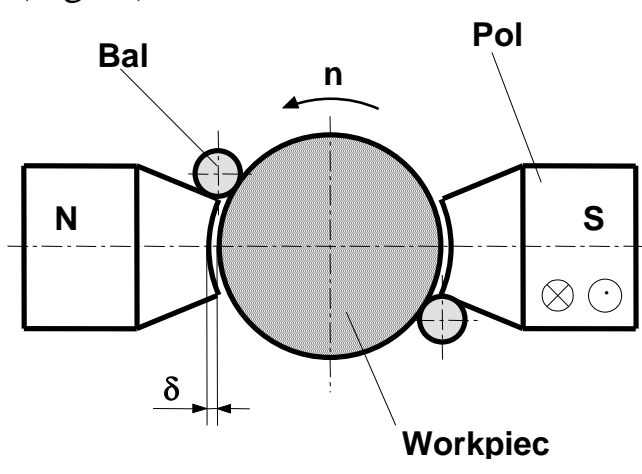

a)

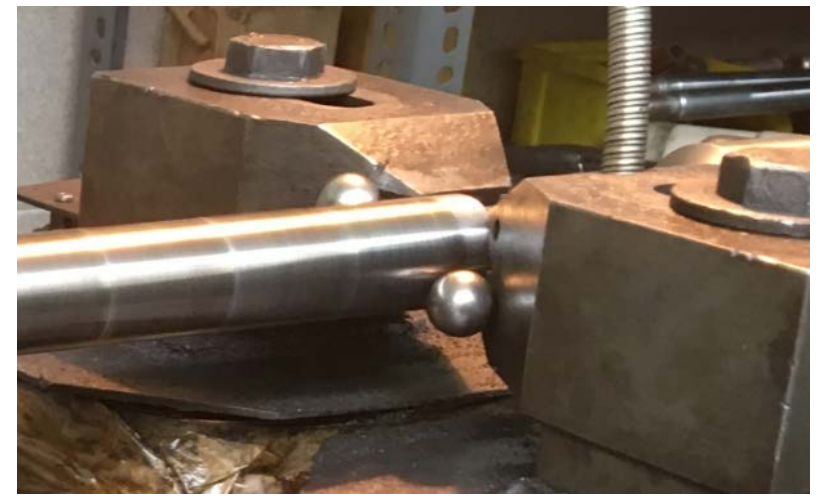

b)

Fig. 4. Process of MABB [14]

As you see this equipment similar to the previously showed equipment of MAP technology, but in this case instead of the abrasive grains were applied two hard bearing balls as the burnishing tools. The balls were set above or under the jaws in radius-shaped slots preventing the balls from any kind of axial displacement. The magnetic force kept the balls in the slots and - depending on the scale of magnetic induction - pressed them to the surface of the workpiece with a force of 50 ... $100 \mathrm{~N}$. The balls could freely roll perpendicularly to the rotational axis of the workpiece following the eventual macro-unevenness of the cylindrical surface. The burnishing operation consisted of a double-stroke motion of the slide along the rotating workpiece, in feed direction.

Important to notice that the MABB process works only with magnetizable materials. In case of a nonmagnetic workpiece the magnetic flux not able to press the ball onto the surface, because the flux cannot take the necessary forms (Fig. 5.).

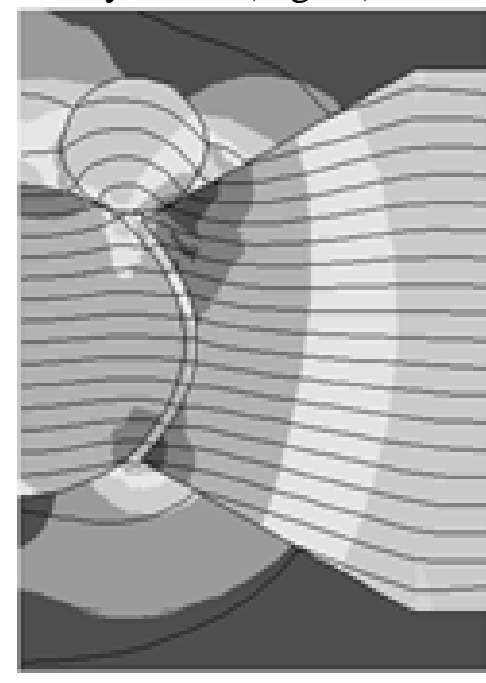

a)

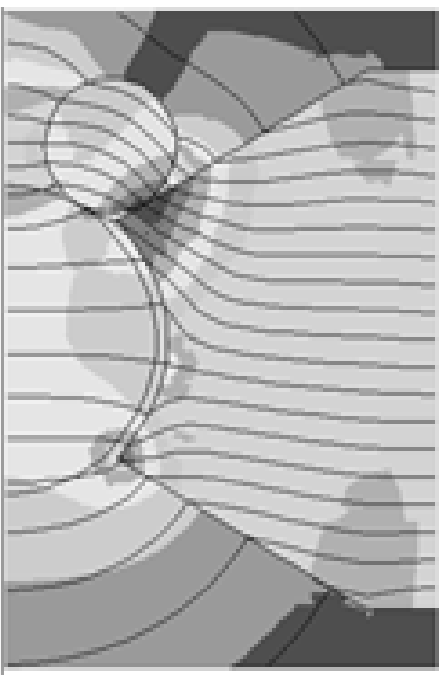

b)

Fig. 5. Magnetic lines for steel a) and Al-alloy b) workpiece material [14]

In case of Fig. 5. b) the ball not rotating and instead of burnishing the ball rubbing the surface which results the destruction of the surface. 


\section{Experimental setup}

In the performed investigations the shaft surfaces were manufactured purposefully by grinding and turning (were used different type of carbide insert). Then the pre machined surface was machined MAM technologies (MABB and MAP). The role of the grinded part (technical parameters of grinding: $\mathrm{v}_{\mathrm{c}}=35 \mathrm{~m} \mathrm{~s}^{-1}, \mathrm{v}_{\mathrm{w}}=10 \mathrm{~m} \mathrm{~min}^{-1}, \mathrm{v}_{\mathrm{f}}=500 \mathrm{~mm} \mathrm{~min}^{-1}, \mathrm{a}=0,02 \mathrm{~mm}$ ) was to be able to compare the surfaces (grinded-turned-burnished-polished). As workpieces of C45-type steel with a diameter of $26 \mathrm{~mm}$ and a length of $100 \mathrm{~mm}$ were selected as processing elements. For cutting wiper geometry (WNMG080404W-MF2, TP2501) and conventional inserts geometry (WNMG080404-MF2, TP2501) was used.

The MAM equipment is able to work as polishing and burnishing function where the electromagnetic poles were fixed onto the slide of the lathe. In the tests the voltage $(U=40 \mathrm{~V})$, current $(\mathrm{I}=10 \mathrm{~A})$ (direct current, adjustable) and the generating magnetic induction $(\mathrm{B}=0,96 \mathrm{~T})$ were the same under burnishing and polishing too. The generated magnetic induction was reduced ( $\mathrm{B}=0,75 \mathrm{~T})$ with polishing grain because of the applied $\mathrm{Al}_{2} \mathrm{O}_{3}$ shielding properties. The magnetic jaws (poles) surrounded the workpiece with a $\delta=3 \mathrm{~mm}$ gap (clearance).

The turning, burnishing and polishing technological parameters see the Table 1.

Table 1. Experimental details

\begin{tabular}{ll}
\hline Turning & \\
\hline$f(\mathrm{~mm} / \mathrm{min})$ & 0,133 \\
\hline$v_{c}(\mathrm{~m} / \mathrm{min})$ & 117 \\
\hline$a_{p}(\mathrm{~mm})$ & 1 \\
\hline Burnishing & \\
\hline$f(\mathrm{~mm} / \mathrm{rev})$ & 0,1 \\
\hline$v_{r}(\mathrm{~m} / \mathrm{min})$ & 22 \\
\hline ball size $(\mathrm{mm})$ & 16 \\
\hline Polishing & \\
\hline grain size $(\mathrm{mesh})$ & $600(25.7 \mu \mathrm{m})$ \\
\hline$t(\mathrm{~min})$ & 1,5 \\
\hline$v_{p}(\mathrm{~m} / \mathrm{min})$ & 62 \\
\hline
\end{tabular}

\section{Evaluation}

After the machining there were seven manufactured surfaces. As first step were measured the surfaces roughens by MITUTOYO Formtracer SV-C3000 roughness tester. The measured results can shown in Table 2.

Table 2. The machined surfaces roughness

\begin{tabular}{clcc}
\hline No. & Technology & $\begin{array}{c}\mathrm{Ra} \\
(\mu \mathrm{m})\end{array}$ & $\begin{array}{c}\mathrm{Rz} \\
(\mu \mathrm{m})\end{array}$ \\
\hline $\mathbf{1}$ & Grinded & 0,54 & 3,43 \\
\hline $\mathbf{2}$ & Turned (simple) & 1,2 & 6,09 \\
\hline 3 & Burnished & 0,40 & 2,40 \\
\hline 4 & Polished & 0,96 & 4,93 \\
\hline $\mathbf{5}$ & Turned (Wiper) & 0,45 & 3,05 \\
\hline 6 & Burnished & 0,27 & 1,92 \\
\hline 7 & Polished & 0,38 & 2,79 \\
\hline
\end{tabular}

Then was measured the twisted surface structure by thread method. This is a simple and fast method because it is only consist of a thread and weight. The thread made from steel, plastic or wool (e.g.: fishing line or sewing thread). In this research were used steel thread where the steel 
diameter of $0,1 \mathrm{~mm}$. The weight depends on the applied thread material and diameter, which in this study was $20 \mathrm{~g}[8]$.

\section{Measuring method}

During the measurement has to rotate the workpiece in horizontal position and superimpose the thread with the weight (Fig 6.)

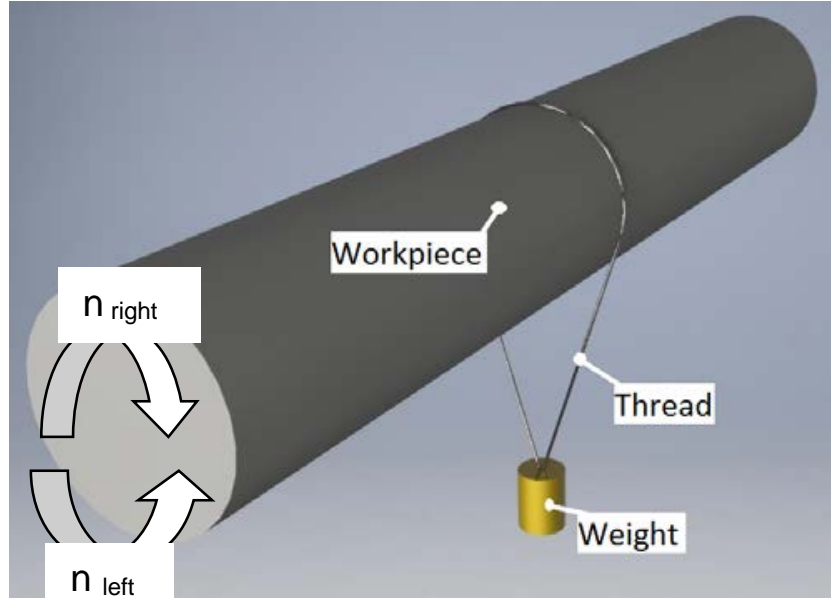

a)

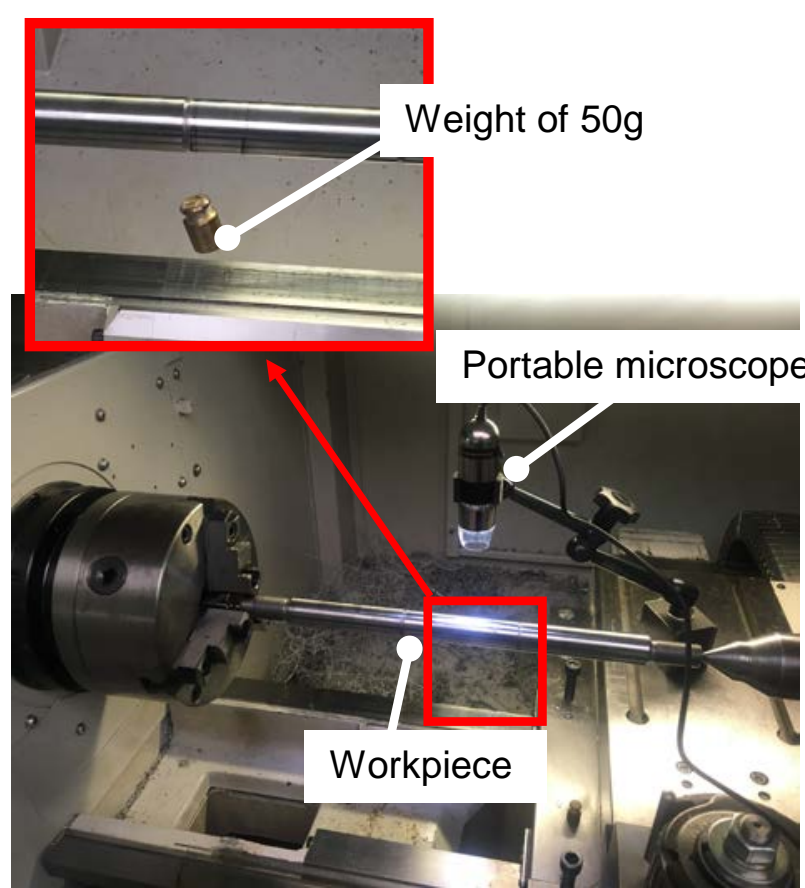

b)

Fig. 6. The measuring method of a) twist and b) displacement of thread

The measuring takes one minute and during this time the workpiece peripheral speed of 20 $\mathrm{m} / \mathrm{min}$. Then have to measure the displacement of thread (a1) by a portable microscope which was fixed on the sledge and must be performed the rotation the other direction and also have to measured it (a2). The average of two values (1) is the characteristic number of twist surface $\left(\mathrm{a}_{\mathrm{m}}\right)$ by [15] industrial standards.

$$
a_{\mathrm{m}}=\frac{a_{1}+a_{2}}{2}
$$

The calculated results (a) and the surfaces roughness (b) are presented in Fig 5.

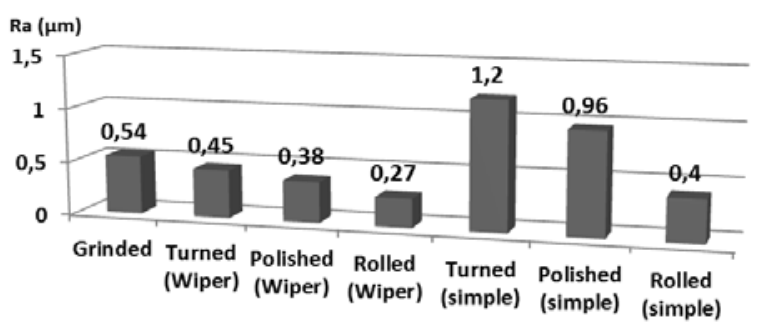

a)

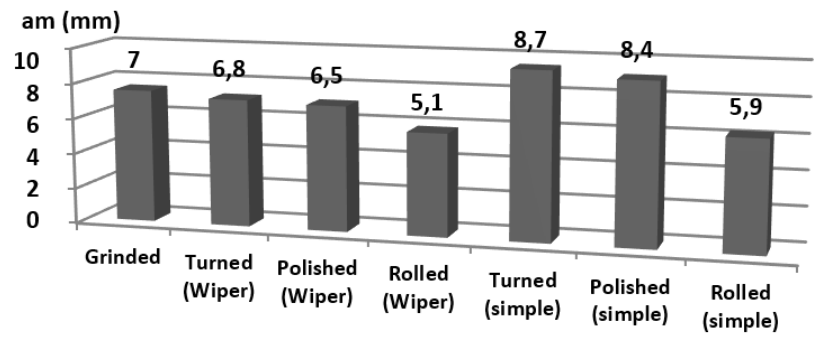

b)

Fig.7. Measurement results of a) Ra roughness and b) characteristic number of twist surface 
The research shows that MAM technologies able to reduce the twisted structure and as a new manufacturing opportunity for surfaces to obtain desired functions such as surfaces with tribological function.

According to the expectations the Wiper insert produced a less than twisted surfaces compared to the simple one and as you see in the Fig 7. the grinded surface were worse than the burnished. So that, instead of grinding can be machined with MAMRB which is faster, economical, easier and some case does not require workpiece transfer. Also there are negatives, like accuracy (size and position) which depends on the previous manufacturing. However, the MAP technology is not able to produce the expected surface.

\section{Acknowledgement}

This research is supported by EFOP-3.6.1-16-2016-00006 "The development and enhancement of the research potential at Pallasz Athéné University" project. The Project is supported by the Hungarian Government and co-financed by the European Social Fund.

\section{References}

[1] S. Jung, W. Haas, Grundlehrang Dichtungstechnik. University of Stuttgart (2006)

[2] G. Lechner, H. Raab, Einfluss der Wellenlaufflache auf das Dichtverhalten von Radialwellendichtringen. Final report, BMWi/AiF Nr. 10670, 1998, pp. 59-73.

[3] J. Kundrák, K. Gyáni, Cs. Felhö, I. Deszpoth, Analysis of lead twist in modern high-performance grinding methods, IOP Conf. Series: Materials Science and Engineering161, 2016, pp.:2-9

[4] J. Schneider, L. Schreiber, Twist-free surfaces through tangential turning, 2002

[5] Yu-Ren Wu, Van-The Tran, Transmission and load analysis for a crowned helical gear pair with twist-free tooth flanks generated by an external gear honing machine Mechanism and Machine Theory 98, 2016, pp.: 36-47

[6] A. Schubert, R. Zhang, P. Steinert, Manufacturing of Twist-free Surfaces by Hard Turning, Procedia CIRP 7, 2013, pp.: 294-298

[7] MBN 31007-7, 2002. Daimler AG, Stuttgard (2001), pp. 312-316

[8] A. Schubert, R. Zhang, P. Steinert, Manufacturing of Twist-Free Surfaces by Hard Turning, Procedia CIRP (2013), pp. 294

[9] J. Kundrák, I. Sztankovics, K. Gyáni, Analysis of the Theoritical Values of Several Characteristic Parameters of Surface Topography in Rotational Turning, WAST International Journal of Mechanical Aerospace, Industrial, Mechatronic and Manufacturing Engineering Vol:8, No:5, (2014), pp. 908

[10] V.K. Jain, Prashant Kumar, P.K. Behera, S.C. Jayswal, Effect of working gap and circumferential speed on the performance of magnetic abrasive finishing process, Wear 250, 2001, pp.: 384-390

[11] Kodácsy, J. Líska: Magnetic Assisted Roller Burnishing and Deburring of Flat Metal Surfaces. Advanced Materials Research Vol. TransTech 472-475 Publication Ltd, Zürich, 2012, pp. 908-911.

[12] Debin Wang, Takeo Shinmura, Hitomi Yamaguchi, Study of magnetic field assisted mechanochemical polishing process for inner surface of Si3N4 ceramic components Finishing characteristics under wet finishing using distilled water, International Journal of Machine Tools \& Manufacture 44, 2004, pp.:1547-1553

[13] V.K. Jain, Prashant Kumar, P.K. Behera, S.C. Jayswal, Effect of working gap and circumferential speed on the performance of magnetic abrasive finishing process, Wear 250, 2001, pp.: 384-390

[14] J. Kodacsy, J. Danyi, A. Szabo, Gy. Fulop: Magnetic Aided Roller Burnishing Metal Parts. 7th International Conference on Deburring and Surface Finishing, UC Berkeley (USA), 2004, pp. 375-378

[15] ZFN 5032:2013-10 (industrial standard) 